\section{Fossils in mélanges}

So-called 'tectonic' mélanges in many parts of the world seem to contain a disproportionately high number of fossils relative to the enclosing rocks. This is particularly true of mélanges in 'greywacke type' terrains, in particular the Esk Head Mélange ${ }^{1}$ in the otherwise sparsely fossiliferous Torlesse Zone of the Alpine Assemblage ${ }^{2}$ in the New Zealand Geosyncline, the mélange belts of the Franciscan Assemblage of California (M. C. Blake, jun., personal communication), and the Liptrap Formation of southern Victoria, Australia. In addition, the fossils contained in mélange belts commonly contain shallow water forms, and in extreme cases even terrestrial fossils (D. L. Jones, personal communication).

These facts alone seem to preclude postdepositional tectonic modification of part of a sedimentary sequence as the sole means of mélange formation. Rather, we suggest that the processes leading to the formation of at least some mélange belts resulted in the development of localised, specialised sedimentary environments during deposition, probably in shallow water and commonly accompanied by submarine volcanism. Continuation of the same tectonic regime, possibly in an accentuated or modified form, then led to the formation of mélange belts in parts of the deposited, but only partly consolidated, sedimentary sequence.

We fully support the suggestion ${ }^{3}$ that the term mélange should be used only in a descriptive sense and that the prefixes 'sedimentary' and 'tectonic' should be used with the utmost caution.

New Zealand Geological Survey,

D. G. BisHOP

PO Box 5342 ,

Dunedin, New Zealand

J. D. BradshaW

Geology Department,

University of Canterbury,

Christchurch, New Zealand

School of Geology,

University of Melbourne,

Victoria, Australia

Received September 30, 1973; revised March 4, 1974.

${ }^{1}$ Bradshaw, J. D., J. R. Soc. N.Z., 3, 161 (1973).

2 Carter, R. M., Norris, R. J., Landis, C. A., and Bishop, D. G., J. R. Soc. N.Z., 4, 5 (1974).

${ }^{3}$ Berkland, J. O., Raymond, L. A., Kramer, J. C., Moores, E. M., and O'Day, M., Bull. Am. Ass. Petrol. Geol., 56, 2295 (1972).

\section{Light scattering from soap films}

IF a strong light beam falls on the surface of a liquid, most of it will be reflected and refracted in certain directions, but a small part will be scattered in all other directions. This light scattering is caused by small surface ripples (corrugations) arising from thermal motion. The scattering intensity is proportional to $k T / \gamma$, where $k$ is the Boltzmann constant, $T$ the absolute temperature and $\gamma$ the surface tension. In the case of a thin, free, liquid film (as found in soap bubbles), the scattered light also contains information about the interaction forces between the two film surfaces. According to the theory of Vrij ${ }^{1}$, the second derivative, $\mathrm{d}^{2} F / \mathrm{d} h^{2}$, of the interaction free energy, $F$, between the two film surfaces, with respect to the film thickness, $h$, can be obtained in this way.

When electrical double layer and van der Waals forces are operative in the film one may write $\mathrm{d}^{2} F / \mathrm{d} h^{2}=B \kappa^{3} \exp (-\kappa h)-$ $A /\left(2 \pi h^{4}\right)$, where $B$ is a function of the surface potential, $\mathrm{K}$ is the reciprocal Debye-Hückel thickness and $A$ is the van der WaalsHamaker constant.
Although a few results have been published ${ }^{1,2}$, no measurements that would corroborate the theory in a completely satisfactory manner have ever been reported. Here we present some results for films drawn from a solution containing $8.2 \times$ $10^{-4} \mathrm{M}$ cetyltrimethylammoniumbromide (CTAB) and 8.4 (weight) $\%$ glycerol. Experiments were carried out on draining films (varying $h$ ) at constant angles. From plots of $\ln \left[\mathrm{d}^{2} F / \mathrm{d} h^{2}+\right.$ $\left.A /\left(2 \pi h^{4}\right)\right]$ against $h$, the values of $\kappa$ were calculated. In the (very small) van der Waals term we used $A=6.28 \times 10^{-20} \mathrm{~J}$. From the values of $\kappa$, the electrolyte concentrations were calculated (Table 1) and compared with the concentration of the solution. The agreement between the two is good, in contrast with older experiments ${ }^{1}$ where the calculated concentrations were up to 16 times too large.

Table 1 Results calculated from the thickness dependence of the light scattering ( $h$ between about 70 and $90 \mathrm{~nm}$ ).

\begin{tabular}{cccc}
\hline $\begin{array}{c}\text { Angle of } \\
\text { incidence }\end{array}$ & $\begin{array}{c}\text { Angle of } \\
\text { observation }\end{array}$ & $\kappa\left(\mathrm{m}^{-1}\right)$ & $\begin{array}{c}\text { Concentration } \\
\text { of CTAB } \\
\left(\mathrm{mol} \mathrm{1} 1^{-1}\right)\end{array}$ \\
$\left(^{0}\right)$ & $\left(^{0}\right)$ & & $8.6 \times 10^{-4}$ \\
60 & 55.0 & $9.78 \times 10^{8}$ & $6.8 \times 10^{-4}$ \\
60 & 54.0 & $8.70 \times 10^{8}$ & $9.6 \times 10^{-4}$ \\
60 & 53.1 & $1.03 \times 10^{9}$ & 9.6 \\
\hline
\end{tabular}

After drainage of a film to constant thickness, we also studied the angular dependence of the light scattering. In Table 2 the observed scattering is compared with values predicted by calculation using the results of the dependence on thickness of the light scattering. It is clear that the experimental results fit the predictions very well.

We conclude that the measurements of the thickness- and

\begin{tabular}{ccc}
\hline Table 2 & \multicolumn{3}{c}{ Angular dependence of the light scattering } \\
\hline $\begin{array}{c}\text { Angle of } \\
\text { observation }\end{array}$ & $\begin{array}{c}\text { Predicted light } \\
\text { scattering ratio }\end{array}$ & $\begin{array}{c}\text { Measured light } \\
\text { scattering ratio }\end{array}$ \\
$(\times)$ & 6.56 & $\left(\times 10^{6}\right)$ \\
54 & 5.86 & 6.69 \\
53 & 4.41 & 5.37 \\
52 & 3.68 & 4.42 \\
51 & 3.10 & 3.78 \\
50 & 2.64 & 3.30 \\
49 & 2.26 & 2.66 \\
48 & 1.69 & 2.34 \\
46 & 1.30 & 1.78 \\
44 & 0.91 & 0.37 \\
41 & 0.60 & 0.63 \\
37 & &
\end{tabular}

angle-dependent light scattering show that the light scattering theory is internally consistent. Further, they show the validity of the exponential thickness dependence of the electrical part of $\mathrm{d}^{2} F / \mathrm{d} h^{2}$.

Part of this work has been carried out with the support of the Netherlands Foundation for Chemical Research (SON) and with financial aid from the Netherlands Organization for Advancement of Pure Research (ZWO).

J. B. RIJNBOUT W. A. B. DONNERS A. VRIJ

van 't Hoff laboratorium,

Transitorium 3,

Padualaan 8,

De Uithof, Utrecht, The Netherlands

Received February 7, 1974.

${ }^{1}$ Vrij, A., J. Colloid Sci., 19, 1-27 (1964). Vrij, A., Adv. Colloid Interface Sci., 2, 39-64 (1968).

${ }^{2}$ Mann, J. A., jun., J. Colloid Interface Sci., 25, 437-441 (1967). 